\title{
An Empirical Research on Study Success in Times of COVID-19 Pandemic - a Case Study
}

\author{
Christin Voigt $^{1 *}$, Jonas Kötter ${ }^{1}$, and Natallia Kukharenka ${ }^{2}$ \\ ${ }^{1}$ Business Administration, Organization and Business Informatics, University of \\ Osnabrueck, Katharinenstraße 1-3, Osnabrueck, 49074, Germany \\ ${ }^{2}$ Didactics of Health and Human Services, University of Osnabrueck, Nelson-Mandela- \\ Str. 13, Osnabrueck, 49069, Germany \\ christin.voigt@uni-osnabrueck.de, jonas.koetter@uni-osnabrueck.de, \\ natallia.kukharenka@uni-osnabrueck.de
}

\begin{abstract}
The COVID-19 pandemic and measures to contain it pushed many universities to switch to online learning in the spring of 2020. The changes took place very quickly and it became clear that the long-term consequences of such a transformation are uncertain and require more detailed study. This research attempts to analyze the impact of online learning on study success. This research makes use of a triangulation with quantitative and qualitative methods. Quantitatively, it contains path diagram with various factors that have an impact on the study success at a German university, which is based on a quantitative online survey with 1.529 participants. Qualitatively, 49 interviews were analyzed in order to identify reasons for the risk of failing to achieve study success. The relevance of technology becomes evident in the quantitative analysis, as it manifests itself in almost all categories that affect study success. Moreover, a new influencing factor appeared, the "adaption to digital teaching", which was often considered important qualitatively.
\end{abstract}

Keywords: Study Success, COVID-19 Pandemic, Higher Education, Study Dropout.

\section{Introduction}

In the spring of 2020, as a result of efforts to contain the COVID-19 pandemic, universities around the world closed for full-time study. This forced university teachers and staff to propose alternative concepts of teaching using digital technologies. As a consequence, the online format replaced quickly traditional classroom concepts. Teaching at many German universities took place exclusively online. However, the introduction of the anti-COVID measures and the rapid transition to online learning made it difficult to think through the long-term consequences of this switch. Experience shows that such quick changes can often cause difficulties, e.g. problems with acceptance among participants of the learning process [1]. Considerable research in the field

\footnotetext{
* Corresponding author
}

(C) 2021 Christin Voigt, Jonas Kötter, and Natallia Kukharenka. This is an open access article licensed under the Creative Commons Attribution License (http://creativecommons.org/licenses/by/4.0).

Reference: C. Voigt, J. Kötter, and N. Kukharenka, "An Empirical Research on Study Success in Times of COVID-19 Pandemic - a Case Study," Complex Systems Informatics and Modeling Quarterly, CSIMQ, no. 29, pp. 17-35, 2021. Available: https://doi.org/10.7250/csimq.2021-29.02

Additional information. Author's ORCID iD: C. Voigt - https://orcid.org/0000-0001-6053-1848. PII S225599222100164X. Received: 31 October 2021. Accepted: 16 December 2021. Available online: 31 December 2021. 
of study success has been conducted before the outbreak of the COVID-19 pandemic. Study success has already been quantified using the indicators of compliance with the standard plan and study period, as well as a low number of dropouts [2]-[7]. Previous studies have focused on students' competencies and long-term success, as well as financial situation, living conditions, counselling and information obtained, study and learning behavior, academic integration, study conditions and physical resources as factors affecting study success [2], [8]-[12]. At the moment, it is still unclear how these factors affect each other during the COVID-19 pandemic and what kind of impact on study success can occur [13]. Therefore, this work deals with the following research questions $(\mathbf{R Q})$ :

RQ1: How can study success at a German university in the time of COVID-19 pandemic be quantitatively explained using a path diagram?

RQ2: Which critical success factors of study success in the time of COVID-19 pandemic can be qualitatively identified?

In this research, we use a triangulation theory. In triangulation theory, two research methods are used in parallel. Thus, the object of research is analyzed from two perspectives. The aim of triangulation is to approach the research object with the help of two different research methods, while the methods used are often of quantitative and qualitative nature [14]. Clark figuratively describes the object of research in triangulation as a triangle approached by two different points [15]. The triangulation theory is chosen, since university closures and the rapid shift to digital teaching are new conditions for many universities. Due to the limited related research available at the current time and the novelty, research from different angles is needed. As one side of the triangle, the study success is described quantitatively using a path diagram. In the diagram, the strength of the influences of different factors becomes visible with the aim of better understanding of the effects on study success at the time of the COVID-19 pandemic and, if necessary, taking measures to prevent dropout at an early stage. With the help of literature review, a holistic model has been developed, which contains all factors affecting study success considered to be important before the pandemic. Since this survey is conducted among enrolled students, only factors relevant for the current semester are taken into consideration. The results were used to compile a quantitative survey, which examined 1.529 students at a German university. The path diagram has already been presented at the 20th International Conference on Perspectives in Business Informatics Research - Workshops and Doctoral Consortium (BIR-WS 2021) [13].

For the second side of the triangulation triangle, a qualitative research is conducted to identify the reasons for learning failure and study success as well as the critical success factors that affect study success of students in the 1st and 3rd semesters. With the help of the qualitative results, the factors that led to a dropout or an extension of the study can be ascertained. Both the quantitative as well as the qualitative research are a case study of a German university.

The theoretical framework with the literature reviews is presented in Section 2. In Section 3, the quantitative research that consists of hypotheses, the data collection, the reliability and factor analysis results, as well as the path diagram is discussed. Section 4 includes the qualitative analysis describing the methods used as well as the quantitative results. Possible recommendations for German universities are given in Section 5 and the research is concluded in Section 6.

\section{Literature Review}

For the starting point of our research, it was important to understand, how study success can be measured. In previous research, the quantification of study success was based on many success factors. For our survey, we have first selected the three most commonly used and, in our opinion, important elements of measuring study success, such as study grade, study completion or dropout, and study duration [13]. Since our research was carried out at the beginning of the semester, it was impossible to collect data on study grade under the conditions of COVID-19. Besides, the number of students, which cancelled at least one course, was taken for further 
analysis. However, cancelling a subject doesn't necessarily lead to a drop out of the university, as the process of study failure is quite long. Instead, we consider the tendency to drop out. Moreover, in case the subject is mandatory, its cancelling can extend the study duration, which is considered to be one more criterion for study success [2], [5]. In this article we determine the study success as a low tendency to drop out, which is expressed in compliance with the curriculum. This compliance includes the achievement of short-term goals (completing courses according to the curriculum) as well as long-term goals (no unscheduled extension of the study program). At this point it should be noted, that successful studying under COVID-19 restrictions is one more criterion for study success during the pandemic [13].

We started our study with two literature reviews according to Schryen [14]. The aim of the first literature review was to find out valid models for measuring the study success and to collect all the influencing factors into one research model. As this research model is designed to identify the direct effects of the COVID-19 pandemic, it does not consider factors such as school or other education. However, lack of specific school knowledge may be one of the reasons for intension to drop out or even for dropping out of the university [15]. It should be mentioned, that no longterm effects of the COVID-19 pandemic on study success can be investigated yet, as the COVID-19 pandemic became a part of our life recently. Instead, the current influence of the COVID-19 pandemic on study success will be examined. Once the model is identified, all factors affecting their relationship to the COVID-19 pandemic will be studied, using the analysis of previous research results obtained in the second literature review [13].

\subsection{Study Success}

To the best of our knowledge, there are no holistic models available at the moment that consider the impact of the pandemic on study success, as not enough time has passed for long-term research. For this reason, the research results that appeared before the COVID-19 pandemic were analyzed. The first literature review was conducted in two languages - English and German and surveyed sources that were not limited to one study course while examining the study success. Figure 1 shows 3 steps of the literature review. In addition, the figure also shows the search string. Furthermore, the search was carried out with corresponding synonyms such as HEI or University. All sources $(n=454)$ in any other languages except English or German, all duplicate publications or not available sources, were excluded (Exclusion 1). Afterwards, the articles were stored and analyzed. Moreover, only scientific articles, that investigate study success or failure were chosen for further analysis. Sources that examine only one influencing factor or have a deviating definition of study success were not considered (Exclusion 2). After that, the sources that describe only one study program or the time before the university were sorted out (Exclusion 3). Finally, the sources were analyzed to find out whether a holistic model of influencing factors could be determined. In the end, a total of six models, which describe study success holistically were revealed [13].

\begin{tabular}{|c|c|c|c|c|}
\hline \multirow{3}{*}{$\begin{array}{l}\text { Search String: } \\
\text { "study dropout" OR "study } \\
\text { success" AND university AND } \\
\text { model AND "influence factors" }\end{array}$} & \multicolumn{4}{|c|}{ 1. Exclusion: General criteria } \\
\hline & $\begin{array}{l}\text { Language } \\
454 \text { left }\end{array}$ & \multicolumn{2}{|c|}{$\begin{array}{c}\text { Duplicate } \\
439 \text { left }\end{array}$} & $\begin{array}{c}\text { Not available } \\
\mathbf{4 2 1} \text { left }\end{array}$ \\
\hline & \multicolumn{4}{|c|}{ 2. Exclusion: Abstract reading } \\
\hline \multirow{2}{*}{$\begin{array}{l}\text { Databases: Google Scholar, } \\
\text { Scopus, Web of Science, ERIC }\end{array}$} & \multicolumn{2}{|c|}{$\begin{array}{c}\text { No scientific source or books } \\
354 \text { left }\end{array}$} & \multicolumn{2}{|c|}{$\begin{array}{c}\text { Wrong focus or too specific } \\
156 \text { left }\end{array}$} \\
\hline & \multicolumn{4}{|c|}{ 3. Exclusion: Full reading } \\
\hline 457 Results & $\begin{array}{l}\text { Focusing on one } \\
\text { study program only } \\
57 \text { left }\end{array}$ & $\begin{array}{r}\text { Focus o1 } \\
\text { study } \\
2\end{array}$ & $\begin{array}{l}\text { n Pre- } \\
\text { lod }\end{array}$ & $\begin{array}{l}\text { No holoristic model } \\
\mathbf{6} \text { left }\end{array}$ \\
\hline
\end{tabular}

Figure 1. Search process $1[13]$

Heublein et al. believe, that a dropout is a result of a long-term process of study failure with several influencing factors. In the so-called pre-study phase, the decision is affected by the 
student's origin, study prerequisites and study choice or entry into the study program. While studying at the university, a combination of factors such as the student's ability to learn, his mental and physical resources, motivation, academic integration, as well as learning conditions is crucial for study success. Moreover, the student's financial situation, living conditions, student support services, received at the moment of making a decision, play an important role while planning to leave the university [10], [11]. On the contrary, Blüthmann et al. consider the admission requirements, as well as study and living conditions, to be the main factors that influence the behavior in studying and learning. The main components of study success are considered to be student satisfaction, the process of obtaining professional and career-relevant knowledge and skills as well as study completed on schedule [9], [8]. In another study, the authors introduce a structural equation model that clarify the impact of dropout tendencies. Study conditions are considered to have the biggest effect on the tendency to drop out $(\beta=-0.26)$. The researchers believe that study conditions influence the social climate at the university, as well as the quality of teaching, student support services, the study content, the organization itself and, as a result, the dropout tendency. At the same time, the study conditions are affected by individual learning speed, sicknesses, lack of information and the social climate. The authors also consider family and work-related stress in their analysis [16]. In addition, Heublein et al. believe that the dropout is affected by the pre-study phase, socio-temporal and structural characteristics, and the study situation. The study situation includes the individual study process as well as internal and external factors [12], [17]. Bornkessel [2] splits all influencing factors into study entry requirements, study-related institutional components, and study-related individual components. They influence study success in a number of ways and reduce the intention to drop out in case the study satisfaction is achieved. Moreover, in his work, Bornkessel explores integration and divides it into teaching and studying components. The integration with teachers takes place if students are treated fair, get enough recognition, find their teachers interesting and accept their accommodation. The integration with students includes communication and professional exchange [2], [13].

In Figure 2 all noticed relationships of these models are depicted. As mentioned before, only the period of active study is taken into account in this article, because the university closure affected the period of study directly. The factors related to the pre-study phase, such as school education, social background or choice of study were not considered. As very short time has passed since the beginning of the pandemic and the long-term consequences cannot be calculated yet, factors such as career prospects or plans are also excluded from the analysis. The following factors are used as latent exogenous variables: physical resources, conditions of study, integration, consulting and information, study and learning behavior, living conditions, and financial situation. According to literature, physical resources cover the resources of both - the student and the university. Some studies put in this category the mental resources, such as selfesteem, which is assigned to study and learning behavior in Figure 2 [8]-[10], [12]. The category conditions of study include institutional conditions, difficulty and scope, the structure, the study climate, teaching quality as well as the study and examination situation, the course size, the content and the organization of the study [2], [8]-[10], [12], [13].

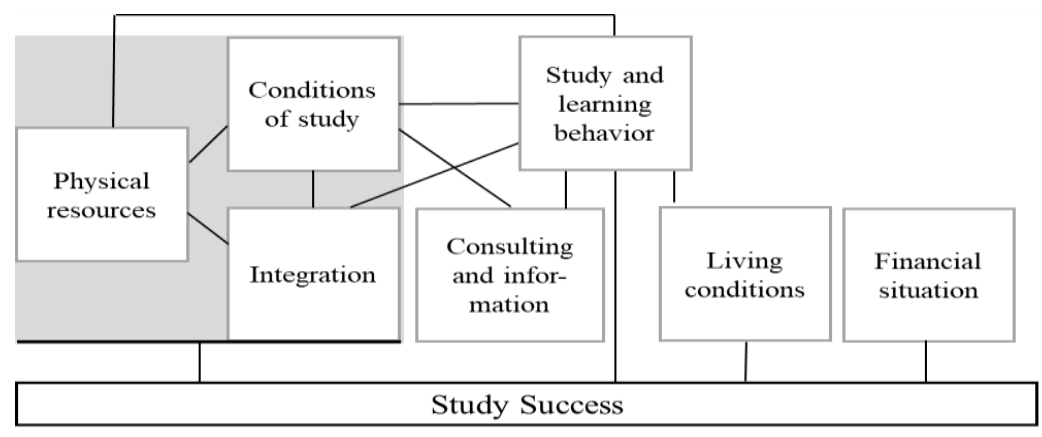

Figure 2. Research model [13] 
Integration can be divided into social and academic integration, thus negative social learning climate is allocated to this category [2], [9], [16], [17]. The three categories, mentioned above mental and physical resources, conditions of study, and integration - influence each other as well as the study success. The study and learning behavior includes such components as learning activities, learning strategies, learning speed, and learning behavior, which are considered to have an impact on learning success in previous research before the COVID-19 pandemic. Conceptual and vocational knowledge and learning difficulties also belong to this category [2], [9], [10], [12], [16]. Student support services as well as help of fellow students are allocated to consulting and information [8], [9], [16]. Some scholars consider social integration to be part of consulting and information. In some research, living conditions are mentioned as context conditions and include such components as the family, personal burdens such as illness or caring for relatives, the living situation or the time spent commuting [2], [8]-[10], [12], [16]. The financial situation, which includes the financing of studies and the employment of students, can also be allocated to the living conditions [9], [10], [12], [13].

\subsection{Study Success in Times of COVID-19 Pandemic}

A second literature review was conducted to determine whether the COVID-19 pandemic affects these factors of study success, as noted in previous studies, and if so, in what way. To this end, research papers relevant to the topic of study success during pandemic were identified on Google Scholar, Scopus, Science Direct, Web of Science, and ERIC with the purpose to shape the quantitative survey items. The following figure shows the used search string. In addition, the search was performed with corresponding synonyms such as HEI or university. A total of 81 publications were identified for the period from 2019 to 2020. In a stepwise process, all publications that were not written in German or English, listed twice, or were not available, have been removed (Exclusion 1). In the second step, non-scientific sources and articles focusing on medical health were excluded (Exclusion 2). In the end, 27 publications remained, which were read and analyzed in a full reading. Those articles with a focus other than study success and nonCorona referenced publications were excluded, leaving seven publications (Exclusion 3). The search process is shown in Figure 3 [13].

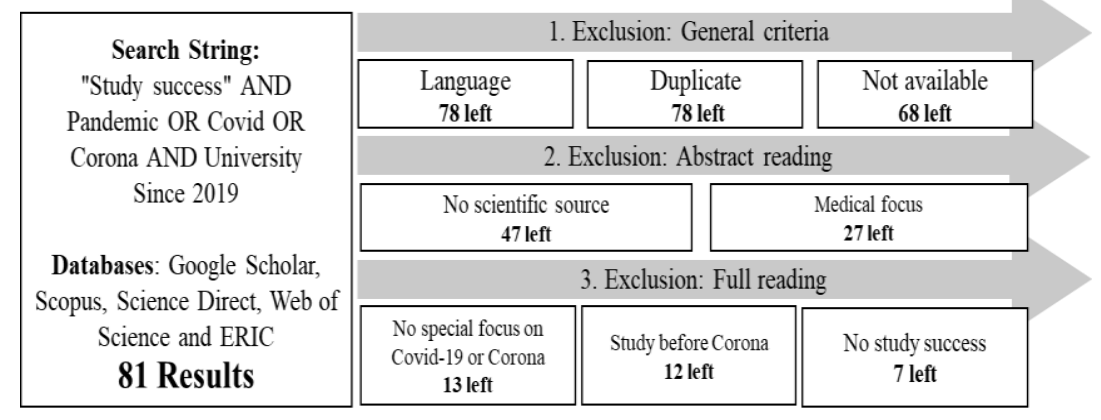

Figure 3. Search process 2 [13]

A concept matrix was constructed on the basis of the seven identified research papers as shown in Table 1. The sources identified were assigned to the categories in this concept matrix. Afterwards, those topics that were included in the research papers were classified to the categories described in Figure 2. In the studies analyzed, different research designs were used, for instance, qualitative interviews and statistical evaluations measuring student success were examined. The items relating on students' prior knowledge were not considered, since those items refer to specific subject content of the courses and not to the studies in general in times of COVID-19 [13]. 
Table 1. Concept matrix [13]

\begin{tabular}{|c|c|c|c|c|c|c|c|}
\hline Source & $\begin{array}{c}\text { Physical } \\
\text { resources }\end{array}$ & $\begin{array}{c}\text { Condition } \\
\text { s of study }\end{array}$ & $\begin{array}{c}\text { Integratio } \\
\mathbf{n}\end{array}$ & $\begin{array}{c}\text { Study and } \\
\text { learning } \\
\text { behavior }\end{array}$ & $\begin{array}{c}\text { Consulting } \\
\text { and } \\
\text { Informatio } \\
\mathbf{n}\end{array}$ & $\begin{array}{c}\text { Living } \\
\text { conditions }\end{array}$ & $\begin{array}{c}\text { Financial } \\
\text { situation }\end{array}$ \\
\hline$[18]$ & $\mathrm{X}$ & $\mathrm{X}$ & $\mathrm{X}$ & $\mathrm{X}$ & $\mathrm{X}$ & $\mathrm{X}$ & $\mathrm{X}$ \\
\hline$[19, \mathrm{~S} .19]$ & $\mathrm{X}$ & $\mathrm{X}$ & & $\mathrm{X}$ & $\mathrm{X}$ & & \\
\hline$[20]$ & $\mathrm{X}$ & $\mathrm{X}$ & & & $\mathrm{X}$ & $\mathrm{X}$ & $\mathrm{X}$ \\
\hline$[21]$ & & $\mathrm{X}$ & $\mathrm{X}$ & & & & \\
\hline$[22, \mathrm{~S} .19]$ & $\mathrm{X}$ & $\mathrm{X}$ & $\mathrm{X}$ & $\mathrm{X}$ & $\mathrm{X}$ & $\mathrm{X}$ & \\
\hline$[23]$ & & & $\mathrm{X}$ & & & & \\
\hline$[24]$ & $\mathrm{X}$ & $\mathrm{X}$ & & & $\mathrm{X}$ & & \\
\hline
\end{tabular}

From the sources listed above, a total of 64 quantitative elements were determined. Most research on study success in times of pandemic consider conditions of study, as shown in column 2 of Table 1, while physical resources, consulting and information, and integration follow. In addition, three of the publications address the study and learning behavior and the living conditions. Moreover, two publications researched the financial situation of students, while the physical resources include students' technical equipment. This equipment usually consists of a laptop or desktop PC, a microphone and a camera, as well as university's software [18]-[20], [22]-[24]. The learning conditions include an evaluation of multiple learning materials, equal opportunities and efficiency [18]-[20], [22]-[24]. In addition, research on study success during pandemic includes items on communication, academic integration and the access to content [18]-[20], [22]-[24]. The study and learning behavior describes the workload and exam behavior [18]-[20], [22]-[24]. Consulting and information consists of the university's advice and points of contact as well as the flow of information between students [18]-[20], [22]-[24], [13].

Living conditions describe the employment, the learning situation at home with the risk of distracting [18]-[20], [22]-[24]. Furthermore, the financial situation includes such components as income and job loss [18]-[20], [22]-[24], [13].

\section{Quantitative Analysis}

\subsection{Quantitative Methods}

The quantitative methods aim to answer the first research question RQ1. To this end, the research model (see Figure 2), that emerged from the literature, including the topics examined in the context of the COVID-19 pandemic, is the basis of the quantitative analysis. This research model results in 16 influencing factors, which are tested using the following hypotheses (H) [13].

H01: The physical resources have an influence on the conditions of study.

H02: The physical resources have an influence on integration.

H03: The physical resources have an influence on the study and learning behavior.

H04: The physical resources have an influence on study success.

H05: The integration has an influence on the conditions of study.

H06: The integration has an influence on the study and learning behavior.

H07: The integration has an influence on study success.

H08: The conditions of study have an influence on study success.

H09: The conditions of study have an influence on the study and learning behavior. 
H10: The conditions of study have an influence on consulting and information.

H11: The study and learning behavior has an influence on integration.

H12: The study and learning behavior has an influence on consulting and information.

H13: The study and learning behavior has an influence on the living conditions.

H14: The study and learning behavior has an influence on study success.

H15: The living conditions have an influence on study success.

H16: The financial situation has an influence on study success.

As shown above, several quantitative items were constructed in line with the literature to address hypotheses H01-H16. The quantitative, voluntary and anonymous survey was available as an online questionnaire to all students of a German university. A total of 1.529 participants filled out the questionnaire. The analysis included data cleaning, the reliability and factor analysis, which was carried out with the help of SPSS. Furthermore, a path diagram using the linear regression and a path analysis was conducted using SPSS AMOS [13].

\subsection{Quantitative Results}

The reliability analysis was conducted to verify the quality of the data. Table 2 shows the Cronbach's alpha of each item when removed from the survey and the corrected item-scale correlation. The following Table 2 illustrates the analyzed initial factors before the factor analysis. In addition, the table contains a labeling of the items which will be used in the following work. The selected items from the factor analysis can be seen in Table 3 . The Cronbach's Alpha had a value of 0.702 before analysis. However, it could be increased to a value of 0.722 by removing the item X1, which addresses the amount of courses that the students have taken compared to the number of courses before the pandemic [13].

Table 2. Reliability analysis [13]

\begin{tabular}{|c|c|c|c|c|c|c|c|}
\hline Item & $\begin{array}{c}\text { C-A } \\
\text { without Item }\end{array}$ & CISC & Initial Factor & Item & $\begin{array}{c}\text { C-A } \\
\text { without Item }\end{array}$ & CISC & $\begin{array}{l}\text { Initial } \\
\text { Factor }\end{array}$ \\
\hline A1 & 0.469 & 0.635 & \multirow{8}{*}{$\begin{array}{c}\text { Study } \\
\text { Conditions }\end{array}$} & H1 & -0.076 & 0.668 & \multirow{3}{*}{$\begin{array}{l}\text { Living } \\
\text { Conditions }\end{array}$} \\
\hline A2 & 0.504 & 0.627 & & $\mathrm{H} 3$ & 0.086 & 0.662 & \\
\hline $\mathrm{D} 2$ & 0.333 & 0.641 & & $\mathrm{H} 2$ & -0.033 & 0.665 & \\
\hline D3 & 0.385 & 0.636 & & F1 & -0.206 & 0.697 & \multirow{2}{*}{$\begin{array}{c}\text { Financial } \\
\text { situation }\end{array}$} \\
\hline E1 & 0.210 & 0.655 & & $\mathrm{~F} 2$ & -0.251 & 0.693 & \\
\hline E2 & 0.302 & 0.645 & & $\mathrm{~J} 2$ & 0.121 & 0.662 & \multirow{4}{*}{$\begin{array}{l}\text { Physical } \\
\text { resource }\end{array}$} \\
\hline G1 & 0.288 & 0.646 & & $\mathrm{~J} 1$ & 0.003 & 0.664 & \\
\hline G2 & 0.357 & 0.639 & & A3 & 0.462 & 0.634 & \\
\hline B1 & 0.547 & 0.627 & \multirow{4}{*}{ Integration } & I2 & 0.023 & 0.663 & \\
\hline B2 & 0.566 & 0.622 & & $\mathrm{C} 2$ & -0.295 & 0.662 & \multirow{3}{*}{$\begin{array}{l}\text { Study } \\
\text { success }\end{array}$} \\
\hline I1 & 0.341 & 0.644 & & C3 & 0.412 & 0.637 & \\
\hline K1 & -0.001 & 0.665 & & $\mathrm{C} 1$ & 0.403 & 0.637 & \\
\hline A4 & 0.437 & 0.631 & \multirow{2}{*}{ Information } & D1 & 0.436 & 0.631 & \multirow{3}{*}{$\begin{array}{l}\text { Study and } \\
\text { learning } \\
\text { behavior }\end{array}$} \\
\hline $\mathrm{K} 2$ & 0.276 & 0.648 & & G3 & 0.475 & 0.647 & \\
\hline & & & & $\mathrm{X} 1$ & -0.042 & 0.722 & \\
\hline
\end{tabular}

The factor analysis aimed to verify the classification of the data and to adjust it to the categories formed. For this purpose, a varimax routing was conducted and, in addition, the extraction was based on the eigenvalue of 1. Furthermore, the Kaiser-Meyer-Measure test was applied, which had a value of 0.85 and, therefore, was acceptable. To determine the number of factors, screen plots as well as the rotated component matrix were analyzed, which results in a total of eleven factors and an significance to Barlet with approximately 0.00. All factors, items, mean values, and standard deviations are shown in Table 3 [13]. 
Table 3. Classification after factor analysis [13]

\begin{tabular}{|c|c|c|c|c|}
\hline $\mathbf{I}$ & Item in survey & $\mathbf{M}$ & SD & FA \\
\hline A1 & $\begin{array}{l}\text { The lecturers successfully manage the preparation and adaptation of teaching } \\
\text { to the circumstances of the digital semester. }\end{array}$ & 3.46 & 0.95 & \multirow{4}{*}{$\begin{array}{l}\text { A: } \\
\text { Conditions } \\
\text { of study: } \\
\text { Adaption to } \\
\text { digital } \\
\text { teaching }\end{array}$} \\
\hline A2 & The digital transfer of the contents is successful. & 3.30 & 1.04 & \\
\hline A3 & I am satisfied with the chosen video conferencing software. & 4.03 & 0.96 & \\
\hline A4 & Teachers pay sufficient attention to the special situations of students. & 3.03 & 1.24 & \\
\hline B1 & $\begin{array}{l}\text { I consider several papers work to be a fair opportunity where equal } \\
\text { opportunities are sufficiently guaranteed. }\end{array}$ & 3.09 & 1.25 & \multirow{2}{*}{$\begin{array}{l}\text { B: Social } \\
\text { integration }\end{array}$} \\
\hline B2 & Communication with students by digital means is functioning. & 4.33 & 1.06 & \\
\hline $\mathrm{C} 1$ & $\begin{array}{l}\text { I am sure that I will successfully complete the courses I have planned during } \\
\text { this semester. }\end{array}$ & 2.76 & 1.10 & \multirow{3}{*}{$\begin{array}{l}\text { C: Study } \\
\text { success }\end{array}$} \\
\hline $\mathrm{C} 2$ & I expect that the COVID-19 pandemic will extend the duration of my studies. & 3.02 & 1.29 & \\
\hline $\mathrm{C} 3$ & $\begin{array}{l}\text { I believe that the realization of my studies is possible during the COVID-19 } \\
\text { pandemic. }\end{array}$ & 3.51 & 1.04 & \\
\hline D1 & $\begin{array}{l}\text { I consider seminar presentations via video conference to be a fair way of } \\
\text { conducting examinations where equal opportunities are sufficiently } \\
\text { guaranteed. }\end{array}$ & 3.28 & 1.26 & \multirow{3}{*}{$\begin{array}{l}\text { D: } \\
\text { Conditions } \\
\text { of study: } \\
\text { seminar }\end{array}$} \\
\hline D2 & $\begin{array}{l}\text { I consider recorded seminar presentations to be a fair way of conducting } \\
\text { examinations where equal opportunities are sufficiently guaranteed. }\end{array}$ & 3.28 & 1.28 & \\
\hline D3 & $\begin{array}{l}\text { I consider oral examination via video conference to be a fair way of } \\
\text { conducting examinations where equal opportunities are sufficiently } \\
\text { guaranteed. }\end{array}$ & 2.94 & 1.31 & \\
\hline E1 & $\begin{array}{l}\text { I consider online exams work to be a fair opportunity where equal } \\
\text { opportunities are sufficiently guaranteed. }\end{array}$ & 3.22 & 1.37 & \multirow{2}{*}{$\begin{array}{l}\text { E: } \\
\text { Conditions } \\
\text { of study: } \\
\text { Exam }\end{array}$} \\
\hline E2 & $\begin{array}{l}\text { I rate online exams as appropriate based on the amount of work they require } \\
\text { compared to the usual exam formats in previous semesters. }\end{array}$ & 3.64 & 1.25 & \\
\hline F1 & $\begin{array}{l}\text { The COVID-19 pandemic has had a negative impact on my financial } \\
\text { situation. }\end{array}$ & 2.88 & 1.35 & \multirow{2}{*}{$\begin{array}{l}\text { F: Financial } \\
\text { situation }\end{array}$} \\
\hline $\mathrm{F} 2$ & I see my studies threatened by a change in my financial situation. & 2.03 & 1.13 & \\
\hline G1 & $\begin{array}{l}\text { I consider several papers as appropriate based on the amount of work they } \\
\text { require compared to the usual exam formats in previous semesters. }\end{array}$ & 3.29 & 1.18 & \multirow{3}{*}{$\begin{array}{l}\text { G: Study } \\
\text { and } \\
\text { learning } \\
\text { behavior }\end{array}$} \\
\hline $\mathrm{G} 2$ & $\begin{array}{l}\text { I judge weekly credit reports to be a fair way of ensuring that equal } \\
\text { opportunities are sufficiently guaranteed. }\end{array}$ & 3.32 & 1.25 & \\
\hline G3 & $\begin{array}{l}\text { My weekly working time that I have to spend on average per course has risen } \\
\text { during the COVID-19 pandemic. }\end{array}$ & 2.36 & 2.12 & \\
\hline $\mathrm{H} 1$ & $\begin{array}{l}\text { There are factors in my home (children, parents, animals) that could prevent } \\
\text { me from learning. }\end{array}$ & 3.62 & 1.90 & \multirow{3}{*}{$\begin{array}{l}\text { H: Living } \\
\text { conditions }\end{array}$} \\
\hline $\mathrm{H} 2$ & $\begin{array}{l}\text { I am more restricted than usual in my study activities by caring for relatives } \\
\text { or looking after children due to the current situation. }\end{array}$ & 1.80 & 1.60 & \\
\hline $\mathrm{H} 3$ & I have a suitable room at my disposal, in which I can study undisturbed. & 4.37 & 1.46 & \\
\hline I1 & I have sufficient access to the content necessary for my courses. & 3.03 & 1.24 & \multirow{2}{*}{\begin{tabular}{|l} 
I: Physical \\
resource \\
and \\
academic \\
integration \\
\end{tabular}} \\
\hline $\mathrm{I} 2$ & I have a laptop or desktop PC that I can use. & 4.53 & 1.28 & \\
\hline $\mathrm{J} 1$ & I have a webcam that I can use. & 4.94 & 0.48 & \multirow{2}{*}{$\begin{array}{l}\text { J: Physical } \\
\text { resource }\end{array}$} \\
\hline $\mathrm{J} 2$ & I have a microphone that I can use. & 4.83 & 0.81 & \\
\hline $\mathrm{K} 1$ & I have organized one or more (online) learning groups. & 4.41 & 0.49 & \multirow[t]{2}{*}{$\begin{array}{l}\text { K: } \\
\text { Information }\end{array}$} \\
\hline $\mathrm{K} 2$ & $\begin{array}{l}\text { I feel sufficiently informed about conducting examinations during the } \\
\text { COVID-19 pandemic. }\end{array}$ & 2.20 & 1.12 & \\
\hline
\end{tabular}

$\mathrm{I}=$ Item, $\mathrm{M}=$ Means, $\mathrm{SD}=$ Standard deviation, $\mathrm{FA}=$ Factor after factor analysis

The first of these identified factors measures adaptation to digital teaching. It summarizes all items that measure adjustment to online education, which includes an implementation of digital 
content and the technological and personal achievement. The adaptation to digital teaching did not appear in previous literature, since the rapid change to online teaching was not necessary before the pandemic. Instead, the items of the factors appeared in the context of the conditions of study, that is why these assumed relations with conditions of study, physical resources, integration, information and study success were tested [13].

The second factor, B, describes social integration in terms of communication between students and perceived equality of opportunity in homework, which are often held in group works. In addition, the previously supposed item classifications of study success are confirmed by the factor analysis, which is a combination of successful completion and the perceived feasibility of studying under the given circumstances. In addition to A, adaptation to digital teaching, study conditions are measured as grading modalities and divided into seminar (D) and examination (E) conditions. This kind of clear distinction is not found in the current literature examined. Conversely, the factor F considers students' financial situation by capturing the impact of the COVID-19 pandemic on their monetary circumstances. Study and learning behaviors are described by the amount of effort invested each week and the grading of assignments and work during the semester for equal opportunity purposes. In addition, living conditions consisted of the space available and the obligations or distracting factors due to working from home. Physical resources, in turn, are divided into Factor J, which includes the physical items of microphone and camera, and Factor I includes the availability of a laptop or desktop PC and access to content. Since at times of the pandemic, face-to-face teaching is no longer possible, the laptop or desktop PC could be the prerequisite for accessing the university content. Thus, factor I turns into a mixture of physical resources and academic integration. Whereas Factor $\mathbf{J}$ measures only the physical resources, microphones and camera, the factor information consists of students feeling sufficiently informed and whether they have learned in one or more digital groups. Since these two items are part of one factor, this could indicate that information is also obtained through social channels, suggesting it is not only university facilities being important for information [13].

All factors after reliability and factor analysis were subjected to a path diagram, which considers the parameters of factor analysis $(\lambda)$ and the relationships between the factors based on maximum likelihood estimator (MSE) of covariances $(\varphi)$, as shown in Figure 4. All items were assumed to be observed variables, while the factors were treated as unobserved variables. The explained variance of the study success in Figure 4 is $47 \%$. Besides, the error terms $(\delta)$ and the items were weighted with the regression weight 1 for each item and factor. The factor information showed no significant influence, since it does not affect conditions of study $(A, D, E)$ or study success $(C)$. The factor information's estimate had a p-label of 0.947 and, therefore, was not significant and is not shown in Figure 4. Also, hypotheses H10 and H12 are not confirmed [13].

In contrast, the estimates of $H$ living condition and $I$ physical resources and academic integration were both significant at the five percent significance level. All the other estimates of observed factors are significant at least at the one percent level of significance. Unlike previous research, no significant influence was given between study success and living conditions, which is why hypothesis H15 is also not confirmed. The missing influence between I and E may occur due to the lack of microphones and cameras required for examinations. Access via laptop or desktop PC is nonetheless necessary for study, hence the factor I has an influence on the factor E $(\phi=0.04)$. Moreover, computers, cameras and microphones are important for seminars as a condition of the study, which is shown by the relation between $I$ and $D(\phi=0.04)$ as well as $J$ and $D(\phi=0.11)$. Hypothesis $\mathbf{H 0 1}$ is confirmed [13]. 


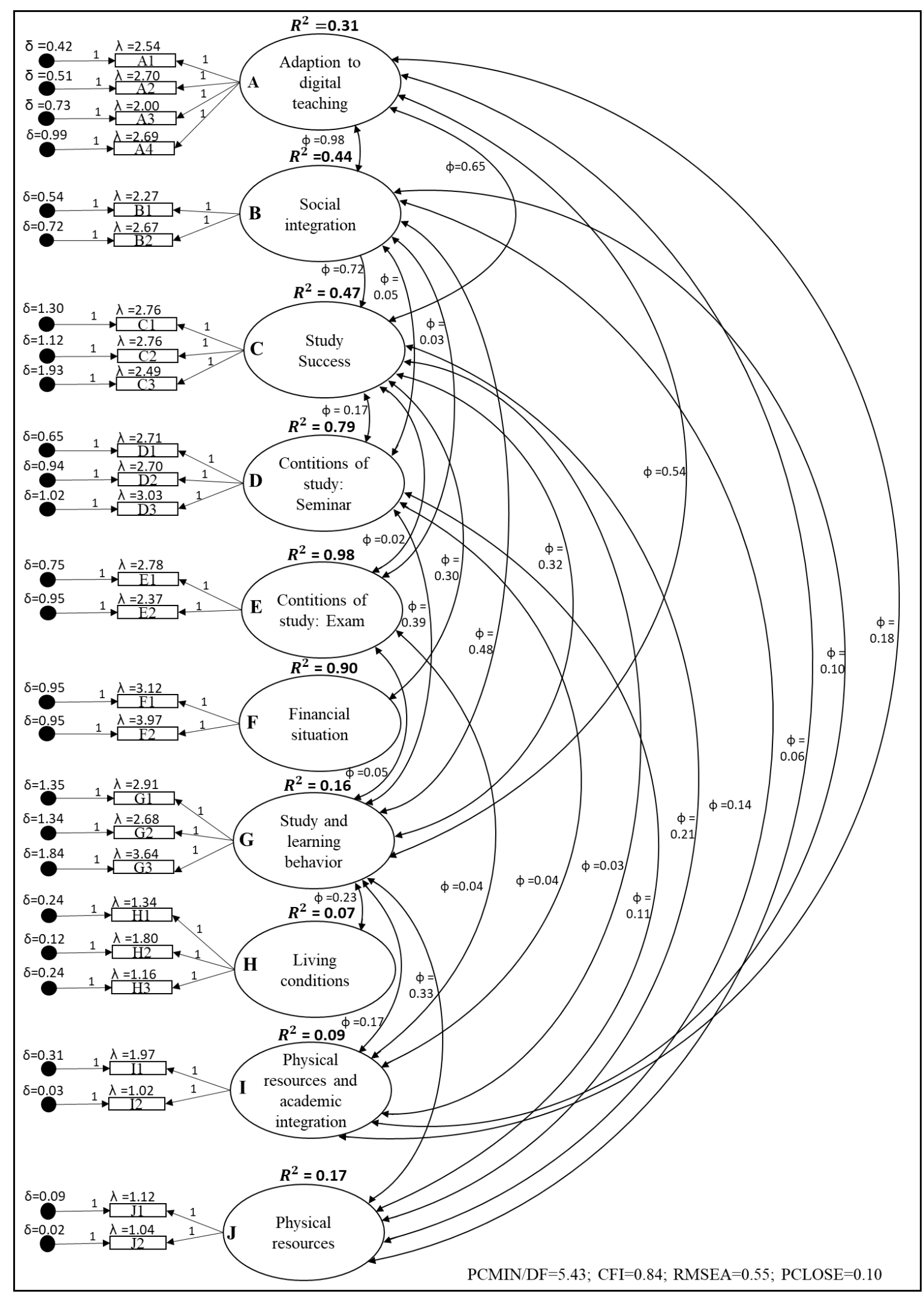

Figure 4. Path diagram of study success in times of COVID-19 [13]

Rather than the lack of effect between living conditions and study success, living conditions have a reciprocal effect on study and learning behavior $(\phi=0.23)$, that is why $\mathbf{H 1 3}$ is confirmed. In the factor analysis, the merging of physical resources with the other factors during the COVID-19 pandemic became clear. Whereas in previous research these could have been clearly delineated prior to the COVID-19 pandemic, technical resources now are of relevance to 
multiple categories such as access to learning content and adaptation to digital teaching as a study condition. All other physical resource influences examined were verified, that is why H02$\mathbf{H 0 4}$ are confirmed. Besides, the impact on integration given by $\mathbf{H 0 5}-\mathbf{H 0 8}$ is confirmed. The strongest factor influencing study success is found by B social integration $(\phi=0.72)$, followed by the adapting to digital teaching as the second strongest factor influencing study success $(\phi=0.65)$. The third strongest influence is given by the study and learning behavior $(\phi=0.32)$, confirming hypotheses H08 and H14 [13].

Moreover, a strong influence on study success is shown by financial situation $(\phi=0.30)$, which confirms hypothesis H16. Furthermore, an influence between conditions of study (factors $A, D, E$ ) and learning behavior (factor $G$ ) can be identified. The highest influence can be noted between $A$ and $G(\varphi=0.54)$, followed by D and $G(\varphi=0.39)$. The lowest influence is between $\mathrm{E}$ and $\mathrm{G}(\varphi=0.05)$. Therefore, $\mathrm{H09}$ is confirmed. The influence between study and learning behavior and integration ( $\phi=0.32)$ also confirms H11. However, the strongest influence in the path diagram is given between adaption to digital teaching and social integration $(\phi=0.98)$. One's opinion on whether the transition to digital instruction is successful seems to depend very much on the success in social integration [13].

\section{Qualitative Analysis}

\subsection{Qualitative Methods}

In addition to the quantitative survey, a panel study was conducted among bachelor students in the digital winter semester 2020 to 2021 answering RQ2. As part of the survey, standardized interviews were performed at the end of the semester. In a random selection process for the panel study, students from the first semester (first-year students) and students from the third semester (advanced students) were included. The study was designed to identify and analyze different views of students at different stages of their studies, e.g., on learning success and the critical influencing factors that affect the dropout. The other panel study surveys are not used for this work. Since the study success of the entire study program could not yet be surveyed qualitatively over this short period of time, the interviews asked about learning success as a successful completion of a course correlating positively with study success [25], [26].

In total, 49 students, 16 male, 31 female and 2 diverse participants from different departments at a German university were interviewed. Of these, 20 interviewees were first semester students and 26 were third semester students. The study was conducted voluntarily. The students received money or certificates for the survey participation, which are obligatory for some study programs. While designing the questionnaire, pretests with eight students were conducted according to the Retrospective Think Aloud technique [27]. Based on this, a standardized interview guide was developed for the three interviewers in order to standardize the process. This was established according to the specifications of Helfferich [28]. The interview was structured as follows. Students had to give a defined number of answers or describe certain conditions adequately so that they could move on to the next question. If the students did not understand the question, it was possible to use follow-up or control questions. In the following section, the questions (Q1, Q2, and Q3) will be presented with the corresponding control questions $(\mathbf{C Q 1}(\mathbf{a}-\mathbf{b}), \mathbf{C Q 2}$ and CQ3(a-c)).

Q1) Have you dropped out of one or more courses? Can you tell us why?

-CQ1a) Can you give us some reasons why you dropped out of the course(s)?

-CQ1b) Why did you drop out of this course?

Q2) Were you able to achieve your individually desired learning success in all courses during the digital semester 2020/2021?

-CQ2) Please describe in which courses you did or did not achieve learning success. 
Q3) Please list and explain three critical success factors in digital teaching.

-CQ3a) Why did you choose this critical success factors?

-CQ3b) What do you understand by this critical success factor?

-CQ3c) What do you think the facets that characterize this success factor are?

The data transcription was conducted by the researchers, who had prepared guidelines on how to handle the transcription in advance [29]. The interviews were analyzed by applying content analysis based on Mayring and Brunner [30]. In an inductive procedure, the dimensions were determined by the researchers. Subsequently, these were compared and merged in a cross-coding procedure.

\subsection{Qualitative Results}

In Q1, students should give reasons why they cancelled one or more courses. 27 students reported that they had not cancelled any courses and 22 students had cancelled or postponed at least one course to the next semester. Five of twenty first-year students ( 22 percent) cancelled or postponed one or more courses in the current semester. 17 of the 27 advanced students (about 62 percent) postponed or cancelled a course in the current semester.

Not only the absolute number of cancelled or postponed exams, but also the reasons that led to cancellation were analyzed. In the study nine dimensions (high workload, missing time, lack of interest, lack of prior knowledge, lack of transferability, low performance, inadequate learning formats, lack of capacities and inadequate technology) were identified from first semester and third semester students. These dimensions were identified for dropping out of a course or postponing a course. Multiple answers were given for the question. Among students who stated to cancel courses, two types of response patterns (postpone the course or drop out of the course) could be identified. By postponed courses, students meant the following: the course was cancelled in the first week, the students did not participate in the course, the course was replaced by another course, the students wanted to complete the course on the second exam date or the course was not offered in the digital semester. Dropping out of courses meant that students had to repeat exams, e.g., because they had failed or paused for personal reasons. For the following analysis, both groups of students (first and third semester) will be considered together. In addition, the term "dropout" will be used further. This includes both postponing and dropping out of courses.

Among the reasons for dropping out of a course is the high workload within a course. A total of ten answers were identified from the interviews. Six answers could be categorized into the dimension of missing time. Students had to drop their courses because of the course overlap with other courses or because they did not have enough time to learn the content. In addition, lack of motivation $(\mathrm{n}=3)$ was cited as a reason for dropping out of courses (lack of interest). The course, which was classified as interesting in advance, turned out to be boring. Another reason for dropping out of courses was the lack of prior knowledge $(\mathrm{n}=3)$. The students did not feel able to complete the exam requirement without first taking the basic courses. The courses that were cancelled were those courses for which basic courses had to be completed first or courses outside the discipline that were not possible without prior knowledge. The fifth dimension is the lack of transferability $(\mathrm{n}=3)$. Students did not realize until the middle of the semester that the course they were attending did not generate credits for their major. In the case of one student, a grade unsatisfactory on examination (low performance) led to the student's dropping out of the course. The dimension of inadequate learning formats resulted in two students dropping out, as one student did not want to participate in a hybrid lecture. The other student reported that the hybrid planned teaching format could not be implemented digitally. For the eighth dimension lack of capacities, two answers could be assigned. Students cancelled the courses, because they registered for too many courses even though they did not want to take them. Two answers could be assigned to the last dimension of inadequate technology. Students who dropped out of their 
course due to technology had no access to learning materials during the semester or had technical problems while taking the exam.

The second qualitative question $\mathbf{Q 2}$ ("Were you able to achieve your individually desired learning success in all courses during the digital semester 2020/2021?") was answered by 48 of the first and third semester students. A total of 15 students (approx. 31\%) claimed that they were able to achieve their defined learning success without restriction. Nine of them were enrolled in the first semester and six in the third semester. In contrast, 17 students (approximately 35\%) were unable to achieve their learning success, seven of whom were enrolled in the first semester and ten in the third semester. In contrast, 16 of the respondents (about 33\%) answered the question with partly/partially, of which eight were enrolled in the first semester and eight in the third semester.

All students who fully achieved their own learning success indicated that they had achieved their own set goals for the semester. These own goals were expressed by either passing the number of events undertaken or achieving satisfactory grades. Learning success depended on one's own goals. For instance, one respondent admitted to never having set himself the goal of getting good grades and to having achieved his individual success solely by passing the exams. Another student saw learning success as the promotion of understanding and motivation. This could not be achieved by two of the students despite the achievement of individual goals. Furthermore, in one case it had not been possible to understand the knowledge and transfer it to long-term memory: "I do not remember a single topic we did in this course." One reason mentioned was the incorrect choice of instructional design. Another reason for a lack of in-depth understanding was the missing communication with fellow students, which was mentioned by three respondents: “...because you do not have anyone to talk to about it if your fellow students are not sitting next door to ask any questions". In addition, the digital exams were criticized by one respondent, because "in any case, it seemed to me that some were much easier, sometimes much more difficult. And that is of course always a point that many people, I would say, are cheating. [...] So, I see the digital exams as somehow questionable". However, one interviewee explicitly stated that he was able to transfer what he had learned to everyday life.

Among the students who indicated a failure of their personal learning success was one respondent who had not taken an exam in the semester at all. All others rated a deviation from the individual plan as a failure. Of these, three students expressed dissatisfaction with the grade they had achieved. Five respondents failed in one or more courses and therefore rated their learning success as not having been achieved. One respondent, in contrast, had passed all the courses in the study program and was satisfied with the grades, but saw no benefit in what he had learned. The content was "foreign to the subject" and could not be transferred to professional life, which in his case was elementary school teaching. Four respondents identified poor organization on the part of the department or the university as the reason for failure. For instance, one student stated that the "events were badly implemented". The poor adaptation to digital teaching also led to "boring and poorly structured" courses and had a negative impact on motivation and the students' own learning success. In addition, students' own time management and motivation were mentioned by four students, "because I think I was pretty lazy in some places when I did not like it and it did not fit." For instance, one student's lack of selforganization led to not taking an exam in the semester at all. Another respondent had "taken on too much". Besides, one student considered the effort to be too high. She commented that it was "not possible" for her to achieve learning success in the digital semester, because "in some subjects it was very problematic that I was overloaded with lectures and assignments." In addition, distraction was cited as a reason by one student. Moreover, in two cases a misconception about the content due to missing or poor learning objectives was mentioned. In another case, the lecturers' teaching ability was also criticized, while in another case, the modules that were planned were not offered, which led to a failure to achieve learning success.

The students who claimed to have partially achieved their learning success did not completely achieve their goals because, for instance, individual courses were not passed or grades were not 
satisfactory. Respondents varied in their ratings of whether learning success was missed or only partially achieved. While some students already considered a failed module as a failure of learning success, others indicated it as partly/partially. Four respondents were dissatisfied with one or more grades, while two had failed in one or more exams. Three students did pass the exams and were satisfied with the grades, but lacked reference and deeper understanding. One of them said "I feel like I am only acting in theory. I don't feel like I'm doing something important." One student noted that the instructor's assistance in achieving learning success had been useful, but unfortunately did not occur until after the student had taken the exam. Another student cited the lack of communication as a reason for the missing deep understanding. In addition, a lack of time management was given as a reason in three cases. For instance, the desire for fixed schedules emerged. Distractions from taking care of a pet or the doorbell ringing were also mentioned as reasons of failure. Two students named time pressure in the exam as a reason: and is it understandable that you make time pressure, but partly it is "inhuman to be able to do that". The poor instructional design led in three cases to only partial achievement of the learning success "but in other modules [...] everything was just recorded. [...] Therefore, the learning success and the motivation suffers, and I did not achieve my desired learning success." One student stated how the digital exam was not suitable for assessing mathematical topics "I would have preferred to write the exam on paper, because then you could have written down your calculation path." Transferability to digital instruction was also difficult for musical subjects, because "I lacked the motivation, the sustained learning, and the music-making in real life. Digitally, it was difficult to manage." One student cited technical problems as a reason for only partially achieving learning success. In another case, a lack of incentive was given as a reason, but "this would also have happened in normal face-to-face study." Positively rated were wellstructured lecturers in one case and the good adaptation and implementation of digital teaching in two cases.

In order to answer research question Q3, we will first define critical success factors. These will be analyzed from the perspective of 1 st semester and 3rd semester students.

Critical success factors are to be defined as those things that have to perform well for the organization or managers to be successful [31]. In the following analysis, the term critical success factors, is understood as those things that are considered extremely relevant for a successful implementation of digital teaching under Covid-19 conditions from the students' point of view.

Figure 5 shows the dimensions (motivation, working environment, technical, teaching formats, interaction and organization) as well as the two groups of students. A total of 147 critical success factors could be classified into the following six dimensions. More details about the dimensions are amalgamated in Table 4.

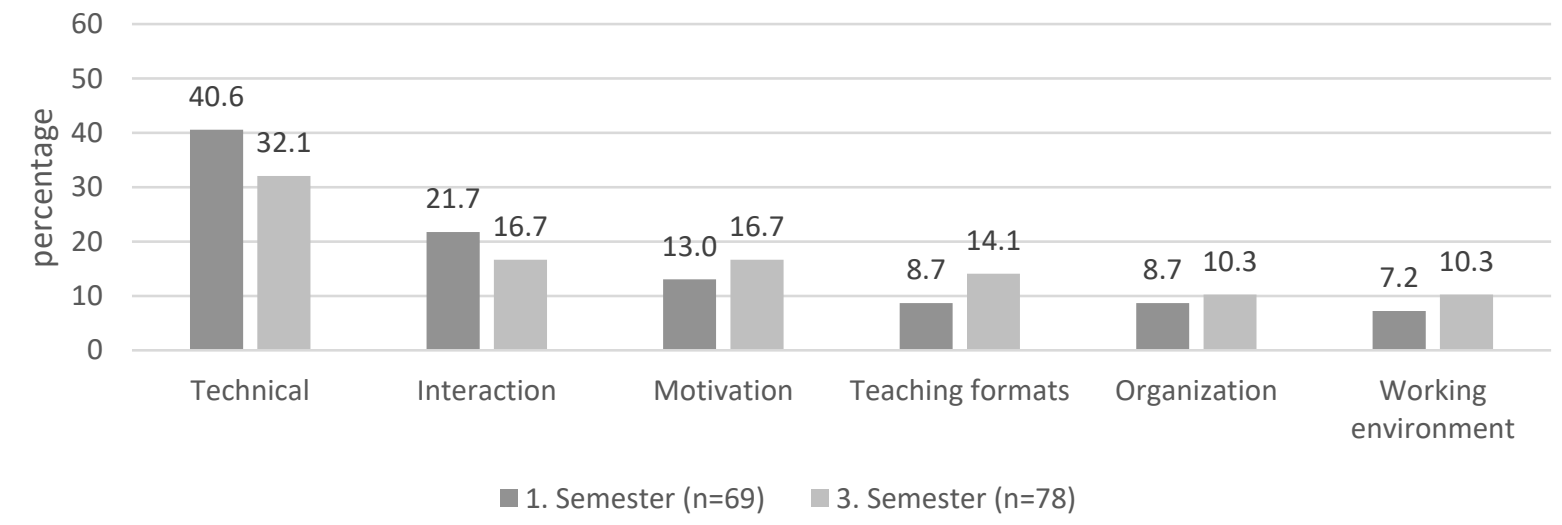

Figure 5. Overview of critical study success factors from students

The technical dimension contains most of the critical influencing factors $(n=53)$. For both first-year and advanced students, access to learning materials is an important factor. Access to 
the university's learning management system is also a critical success factor for both groups of students. The 1st semester students specifically defined the introduction to the system as a critical success factor, because they have no experience with the system. In the dimension interaction, a semester comparison shows that students in the first semester rate communication with other students as a critical success factor. The second most frequently mentioned dimension called interaction $(\mathrm{n}=28)$. In these dimensions, a semester comparison shows that students in the first semester rate communication with other students as a critical success factor. 3rd semester students are more likely to rate communication with lecturers or support as a critical success factor. In total, the dimension of motivation was mentioned 22 times. Third semester students listed the fun of the course as a critical success factor in this dimension. In addition, two first-semester students indicated that success also depends on extracurricular activities such as sports. For the fourth most frequently mentioned dimension (teaching formats $(n=17)$ ), the groups of students all answered very similarly. For both groups, it is important that there is sufficient practice time to study the content and that exams are based on the content from the course. In addition, 3rd semester students identified that the innovative format of a course and the structure of the course were considered as critical success factors. Both groups of students described the dimension organization $(n=14)$ as a critical success factor that is defined by one sub-dimension (self-organization). 13 answers were found in the dimension working environment. Distracting factors such as an area without distractions for learning were named as critical success factors in this dimension.

Table 4. Critical study success factors from students

\begin{tabular}{|c|c|c|c|c|}
\hline Main-Dimension & Sub-Dimension & 1. Semester & 3. Semester & $\sum$ \\
\hline \multirow{8}{*}{ Technical } & $\begin{array}{l}\text { Access to the Learning Management } \\
\text { System }\end{array}$ & 3 & 6 & 9 \\
\hline & Technical equipment & 7 & 5 & 12 \\
\hline & Access to learning materials & 10 & 9 & 19 \\
\hline & Permanent internet connection & 2 & 3 & 5 \\
\hline & Introduction to technical conditions & 3 & 0 & 3 \\
\hline & Infrastructure & 1 & 1 & 2 \\
\hline & Usability & 1 & 0 & 1 \\
\hline & Offline availability & 0 & 1 & 1 \\
\hline \multirow{2}{*}{ Interaction } & Students & 11 & 5 & 16 \\
\hline & Lectures and Support & 4 & 8 & 12 \\
\hline \multirow{7}{*}{ Motivation } & Fun during studies & 2 & 7 & 9 \\
\hline & Perseverance & 2 & 2 & 4 \\
\hline & Self-reflection & 1 & 0 & 1 \\
\hline & Monotony & 0 & 1 & 1 \\
\hline & Emotional health & 1 & 0 & 1 \\
\hline & Interest in the discipline & 1 & 3 & 4 \\
\hline & Extracurricular activities & 2 & 0 & 2 \\
\hline \multirow{5}{*}{ Teaching formats } & Innovative formats & 0 & 2 & 2 \\
\hline & Passing exams & 3 & 4 & 7 \\
\hline & Regular upload of learning materials & 1 & 1 & 2 \\
\hline & Clear structure & 0 & 2 & 2 \\
\hline & Practice times & 3 & 2 & 5 \\
\hline Organization & Self-organization & 6 & 8 & 14 \\
\hline \multirow{3}{*}{$\begin{array}{l}\text { Working } \\
\text { environment }\end{array}$} & Distracting factors & 3 & 6 & 9 \\
\hline & Work life balance & 1 & 1 & 2 \\
\hline & Missing campus life & 1 & 1 & 2 \\
\hline
\end{tabular}




\section{Recommendations for Action}

The items included in the quantitative survey after the literature review and factor analysis indicated, technology is present in almost all categories that influence study success. For instance, adaptation to digital teaching includes video software, while study conditions are related to examination and seminar and also include technology for content presentation. Moreover, the access to content depends on the desktop PC or laptop and the social integration and information relies on the digital media required to interact with fellow students [13]. Furthermore, the qualitative interviews showed how reliable information, such as a frequent upload of material, are also crucial for the success in studies. Using our findings, we can prevent the long-term risk of dropout and enhance student success. Thus, for instance, a technical support could be provided and programs to promote social integration could be established. Beyond that, by raising awareness of students' personal barriers, study and learning conditions can be adjusted to fit their living situations. Similarly, our results have shown a difference between the conditions for seminars during the semester in digital teaching and those for examinations, which differ regarding living conditions or distracting factors as well as in terms of the technical equipment required or the social interactions with fellow students and teachers. This result was also evident in the qualitative interviews. Contemporary technical equipment for students is particularly important for homework and seminars. Study programs could be adapted either to the technical equipment or the technical equipment could be improved. Nevertheless, the strongest impact was indicated for the new factor of the path diagram adaptation to digital teaching, which underlines the importance of university preparation [13]. The influence of adaptation to digital teaching also emerged in the qualitative interviews. A well-structured hybrid teaching concept with confident use of the digital elements was able to increase motivation and study success in some cases.

Along with the category of adaptation to digital teaching, social integration of the path diagram and interviews needs to be accounted for as well. Communication and interaction in distance learning is the focus of this category, which stays out by the high variance between these and physical resources and academic integration in the path diagram. Qualitatively, on the one hand, the interaction between students both in learning and in leisure time was named as a condition for success and, on the other hand, the interaction between students and teachers as a positive influence on study success. As a recommendation, digital advising rooms could be provided to achieve intentional interaction in the digital semester between instructors and students. However, it should also be mentioned that although there are advantages to digital communication, such as without attendance required, students' weekly work hours have increased in the path diagram (study and learning behavior), digital formats must be restructured and revised (conditions of Study: Seminar). In addition, the study conditions need to be reevaluated according to the effort of the digital space (conditions of Study: Exam). In order to enable equal opportunities, efforts should be made to ensure that students have sufficient access to courses (physical resource and academic integration), because seminar lectures or presentations (conditions of Study: Seminar) are held online. Thus, students need a laptop or computer, a webcam (physical resource and academic integration), and a microphone (physical resources). The university could provide workstations for students who do not have sufficient internet access to take exams. However, this is only possible in individual cases due to contact restrictions. Regarding our case, $1.1 \%$ of all respondents of the quantitative survey indicated that they did not have a suitable technical device at their disposal. Towards this end, the university could also acquire its own stock of laptops (physical resources) to support these students (financial situation) [13]. In addition, some interviewees found it difficult to motivate and organize themselves in distance learning, which in some cases led to failure and dropouts. Lack of fun, perseverance, and interest, as well as distracting factors, were some of the reasons given. In contrast, a clear structure and good organization by the teachers were seen as helpful to achieve learning success. For this purpose, learning plans and frequent learning success controls 
could be provided in order to prevent students from losing focus. Similarly, the possibility of synchronous feedback using video conferencing systems to inform an online consultation session could have a positive effect on comprehension, as one respondent explicitly stated having been able to understand the content after personal contact with the lecturer.

\section{Conclusion}

The aim of this article was to investigate how study success at a German university during the COVID-19 pandemic can be described and which critical success criteria of study success can be identified. To this end, a triangulation was used that combines quantitative and qualitative methods. For the quantitative analysis, previous literature was first searched for holistic models to describe study success. The categories found were examined in terms of previously researched influences of the COVID-19 pandemic, forming the basis for the analysis. With regard to the reliability and factor analysis, a new factor, adaptation to digital teaching, emerged that has a strong influence on study success, social integration, and study and learning behavior. Furthermore, our analysis demonstrated that technology plays a significant role in almost all areas and cannot be isolated from other factors [13]. The qualitative analysis includes three question of an interview in which 49 first and third semester students participated and showed the importance of communication with fellow students and teachers. Besides, motivation and time management play a significant role in the study success during the pandemic.

From this research, recommendations for action can be derived for German universities to increase study success during the COVID-19 pandemic and to learn for future university teaching. Thus, for instance, institutional facilities for advising students and teachers could be created. In particular, digital communication and technical advices and equipment seem to be relevant in the current situation.

Even though we have conducted our work carefully, it is not free of limitations. Since its parameter was not significant, the results of the factor information of the path diagram must be critically questioned. In addition, both the quantitative and qualitative study is a case study and, therefore, limited to the German university examined. Universities located in other cultures or with other technical requirements might have different experiences, as political and higher education policy decisions also have a huge impact on the results. The German university switched to distance learning during the semester, while other universities following an hybrid approach might have had different experiences. Besides, the path diagram shown in Figure 4 explains the influences in distance learning during the COVID-19 pandemic only. Factors with no relation to the pandemic were excluded in the research model. Moreover, some conceivable relationships such as the living conditions influencing factors $\mathrm{D}$ and $\mathrm{E}$ might have not been considered. Moreover, this study deliberately concentrates on the impact on undergraduates already enrolled at university. However, previous studies have demonstrated how schooling in particular affects the dropout rate at German universities [13], [32].

Future research could examine the effects of home-schooling on long-term study success. Because study and exams were conducted at home, disruptive factors could have an impact stronger than before. Related to this, further studies could investigate the effects of the lack of learning spaces and libraries during university closures. Nevertheless, attention should also be given to treating distance learning as an opportunity for students during the COVID-19 pandemic. In addition to more technical innovations in the facilities and new teaching concepts, it also offers more freedom and flexibility. As noted in previous research, it eliminates the time required for commuting. Besides, childcare as well as part-time work might be easier to coordinate while studying remotely. Further studies might be conducted to determine which students were mostly influenced positively by distance learning and which students were mostly influenced negatively by it [13]. 


\section{References}

[1] S. Dunphy and P. A. Herbig, "Acceptance of innovations: the customer is the key!" The Journal of High Technology Management Research, vol. 6, no. 2, pp. 193-209, 1995. Available: https://doi.org/10.1016/10478310(95)90014-4

[2] P. Bornkessel and D. Z. für Hochschul, "Erfolg im Studium: Konzeptionen, Befunde und Desiderate,” 2018 (in German).

[3] A. Gold, Studienabbruch, Abbruchneigung und Studienerfolg: Vergleichende Bedingungsanalysen des Studienverlaufs. Lang, 1988 (in German).

[4] H. Meulemann, „Zufriedenheit und Erfolg in der Bildungslaufbahn. Ein Längsschnitt vom Gymnasium bis zum Studienabschluss“, Zeitschrift für Sozialisationsforschung und Erziehungssoziologie, vol. 11, no. 3, pp. 215-238, 1991 (in German).

[5] H. Schmidtmann and J. Preusse, "Soziodemografie, Studienmotive und Studienerfolg beruflich qualifizierter Studierender: Befunde an der Fern-Universität in Hagen," Beruflich Qualifizierte im Studium, p. 101, 2015 (in German).

[6] A. Winteler, Pfadanalytische Validierung eines konzeptionellen Schemas zum Studienabbruch. Institut für Empirische Pädagogik, Pädagogische Psychologie und ..., 1984 (in German).

[7] T. T. York, C. Gibson, and S. Rankin, "Defining and measuring academic success," Practical Assessment, Research, and Evaluation, vol. 20, no. 1, p. 5, 2015.

[8] I. Blüthmann, "Individuelle und studienbezogene Einflussfaktoren auf die Zufriedenheit von Bachelorstudierenden," Zeitschrift für Erziehungswissenschaft, vol. 15, no. 2, pp. 273-303, 2012 (in German). Available: https://doi.org/10.1007/s11618-012-0270-3

[9] I. Blüthmann, S. Lepa, and F. Thiel, "Studienabbruch und-wechsel in den neuen Bachelorstudiengängen," Zeitschrift für Erziehungswissenschaft, vol. 11, no. 3, pp. 406-429, 2008 (in German). Available: https://doi.org/10.1007/s11618-008-0038-y

[10] U. Heublein, C. Hutzsch, J. Schreiber, D. Sommer, and G. Besuch, "Ursachen des Studienabbruchs in Bachelor-und in herkömmlichen Studiengängen", Ergebnisse einer bundesweiten Befragung von Exmatrikulierten des Studienjahres, vol. 8, no. 2, 2007 (in German).

[11] U. Heublein and A. Wolter, "Studienabbruch in Deutschland. Definition, Häufigkeit, Ursachen, Maßnahmen," Zeitschrift für Pädagogik, vol. 57, no. 2, pp. 214-236, 2011 (in German).

[12] S. Isleib, A. Woisch, and U. Heublein, "Ursachen des Studienabbruchs: Theoretische Basis und empirische Faktoren," Zeitschrift für Erziehungswissenschaft, vol. 22, no. 5, pp. 1047-1076, 2019 (in German). Available: https://doi.org/10.1007/s11618-019-00908-x

[13] C. Voigt and J. Kötter, "Understanding the Impact of the Corona Pandemic on the Study Success at a German University," Joint Proceedings of the BIR 2021 Workshops and Doctoral Consortium co-located with 20th International Conference on Perspectives in Business Informatics Research (BIR 2021), Vienna, Austria, vol. 2991, Ceur-ws.org, pp. 1-15, 2021.

[14] N. K. Denzin, Research act. Aldine Publishing Chicago, 1970.

[15] D. Clark, "Plane and Geodetic Surveying for Engineers," Constable, vol. 2, 1951.

[16] I. Blüthmann, F. Thiel, and C. Wolfgramm, "Abbruchtendenzen in den Bachelorstudiengängen. Individuelle Schwierigkeiten oder mangelhafte Studienbedingungen?" Die Hochschule: Journal für Wissenschaft und Bildung, vol. 20, no. 1, pp. 110-126, 2011 (in German).

[17] U. Heublein et al., "Zwischen Studienerwartungen und Studienwirklichkeit,” 2017, vol. 1, pp. 134-136 (in German).

[18] T. Ngambi, J. Brown, F. Grossi, S. Choudhury, P. Baylis, and S. Overton, "Retention, Success and Progression amongst Foundation Year Students: the effects of the transition to online learning as a result of the COVID-19 Pandemic-A Case Study,” 2020.

[19] S. Mahmood, "Instructional Strategies for Online Teaching in COVID-19 Pandemic," Human Behavior and Emerging Technologies, vol. 3, no. 1, pp. 199-203, 2021. Available: https://doi.org/10.1002/hbe2.218

[20] T. Reis and M. Grady, "Doctoral Advising in COVID-19: Opportunity for Change," International Journal of Multidisciplinary Perspectives in Higher Education, vol. 5, no. 1, pp. 136-136, 2020. Available: https://doi.org/10.32674/jimphe.v5i1.2652 
[21] J. Bartz, "All Inclusive?! Empirical Insights into Individual Experiences of Students with Disabilities and Mental Disorders at German Universities and Implications for Inclusive Higher Education," Education Sciences, vol. 10, no. 9, p. 223, 2020. Available: https://doi.org/10.3390/educsci10090223

[22] P. Klein et al., "Studying physics during the COVID-19 pandemic: Student assessments of learning achievement, perceived effectiveness of online recitations, and online laboratories," Physical Review Physics Education Research, vol. 17, no. 1, p. 010117, 2021. Available: https://doi.org/10.1103/PhysRevPhysEducRes.17.010117

[23] M. Pumptow and T. Brahm, "Students' Digital Media Self-Efficacy and Its Importance for Higher Education Institutions: Development and Validation of a Survey Instrument," Technology, Knowledge and Learning, vol. 26, pp. 555-575, 2021. Available: https://doi.org/10.1007/s10758-020-09463-5

[24] Q. Zhang, "Narrative Inquiry into Online Teaching of Chinese Characters during the Pandemic," International Journal of Chinese Language Teaching, vol. 1, no. 1, p.20, 2020.

[25] L. Huber, "Von 'basalen Fähigkeiten 'bis' vertiefte Allgemeinbildung': Was sollen Abiturientinnen und Abiturienten für das Studium mitbringen?" Gymnasiale Bildung zwischen Kompetenzorientierung und Kulturarbeit, Springer, pp. 107-124, 2009 (in German). Available: https://doi.org/10.1007/978-3-531-914855_8

[26] M. Schwinger, L. Wirthwein, G. Lemmer, and R. Steinmayr, “Academic self-handicapping and achievement: A meta-analysis," Journal of Educational Psychology, vol. 106, no. 3, pp. 744-761, 2014. Available: https://doi.org/10.1037/a0035832

[27] T. Lenzner, C. Neuert, and W. Otto, "Kognitives Pretesting (Version 1.1)," GESIS Survey Guidelines, 2015 (in German). Available: https://doi.org/10.15465/GESIS-SG_010

[28] C. Helfferich, Die Qualität qualitativer Daten. Wiesbaden: VS Verlag für Sozialwissenschaften, 2011 (in German). Available: https://doi.org/10.1007/978-3-531-92076-4

[29] P. Mayring, "Qualitative inhaltsanalyse," in Handbuch qualitative Forschung in der Psychologie, Springer, pp. 495-511, 2020 (in German). Available: https://doi.org/10.1007/978-3-658-26887-9_52

[30] P. Mayring and E. Brunner, "Beiträge zur Qualitativen Inhaltsanalyse-Die Schriftenreihe des Instituts für Psychologie der Alpen-Adria-Universität Klagenfurt stellt sich vor,” 2006 (in German).

[31] G. Mey and K. Mruck, Handbuch Qualitative Forschung in der Psychologie. 2010 (in German). Available: https://doi.org/10.1007/978-3-531-92052-8

[32] T. K. Hailikari and A. Nevgi, "How to diagnose at-risk students in chemistry: The case of prior knowledge assessment," International Journal of Science Education, vol. 32, no. 15, pp. 2079-2095, 2010. Available: https://doi.org/10.1080/09500690903369654 